\title{
Further educations: transformative teaching and learning for adults in times of austerity
}

This is a draft of a published paper.

Citation: Duckworth, V. and Smith, R. 2018. 'Further educations: transformative teaching and learning for adults in times of austerity'. In: Boeren, E. \& James, N. (2018). Being an adult learner in austere times. London: Palgrave-Macmillan.

This material is subject to copyright

Vicky Duckworth and Rob Smith

\section{Introduction}

In this chapter, a decade on from the financial crisis that heralded the introduction of austerity measures in the UK, we will outline our perspective on the impact of cuts on adult participation in further education. Then, through reference to the FE in England:

Transforming Lives and Communities research project - a study that set out to identify and celebrate examples of transformative teaching and learning in further education - we will illustrate how further education still transcends its reductive and instrumentalist neoliberal purposing by providing a counter-hegemonic and 'differential' space for adult learners. Evidence from the project shows how despite straitened finances and the constraints of a constantly-changing annual funding methodology that incentivises college self-interest and gaming, further education providers continue to empower people and their communities. In doing so, they challenge intergenerational inequality and enhance agency and hope.

Since Prime Minister Jim Callaghan's Great Debate speech of 1976, the policy agenda in the UK has placed an increasingly instrumentalist onus on compulsory education to connect with the needs of industry. The Further and Higher Education Act of 1992 incorporated further education colleges, thereby laying the ground for a transformation of their role away from being historically rooted, organic expressions of local and municipal industrial need and into agents of national economic and skills policy (Smith 2013). The Act restructured educational provision for adults and young people over the age of 16 and connected the new further education 'sector' through the umbilicus of a newly devised funding methodology to central government. Apart from the erosion of further education teachers' working conditions and a series of disruptive re-regulations of their professional status, the last quarter century has been characterised by a string of policy interventions (for example, General National Vocational Qualification (1994), Modern Apprenticeships (2001), Train to Gain (2006), Entry to Employment (2003), the 14-19 diploma (2008) and the launch of 'New' Apprenticeships (2017), see Smith and O'Leary 2015: 176) many of these having a significant impact on college teachers' work and students' learning experiences. While there was a policy commitment to lifelong learning during this period, since 2009 this has increasingly fallen by the wayside. The focus instead has been on 16-19 provision, the recent setting of a target for the recruitment of 3 million apprentices by 2020 being the latest example in a line of 'new' vocational qualifications.

\section{Contextual constraints: Notions of the Knowledge Economy}


In the UK and internationally, democracy and notions of community are being (re)conceptualized in our public institutions through the lens of neoliberal ideology. Neoliberalisation is the dominant political force of our time, bringing with it a focus on deand re-regulation, economic competitiveness (both national and institutional) all framed by discourses of globalisation (Davies 2014). This has resulted in so-called 'free market' competition displacing social democratic policy as a structuring force in many areas of public life. Under the premise of building a 'knowledge economy', the central duty of the nation's education system is assumed to be to provide a flexible, adaptable and skilled workforce to make the country competitive in the globalised economy. The knowledge economy is a hypostatised concept that positions education instrumentally as a conduit and a sorting house through which the population is processed in order to provide human capital (Becker 1993). Interestingly, the two tier (academic versus vocational) system that has long been entrenched in the English context consequently reifies a cleavage in the traditional bell curve of ability (Dorling 2014, 46-9) resulting in a bi-sected bell curve. The notion of IQ that has long formed the underpinning measure for academic achievement across the ability ranges being added to by an amorphous notion (and even more suspect in terms of measurability) we might call employability quotient or EQ. Between the two, education institutions are structurally positioned as providers with a responsibility to supply human capital with an EQ sufficient to fulfil the 'skills needs' of employers.

While neoliberal educational policy often pays lip-service to social justice through the discursive vehicle of social inclusion (Hope 2002), behind this promise of social mobility through educational attainment is a 'skills discourse' (Smith and O'Leary 2015: 175) that depends upon the objectification of students and their stratification within an intractable structure that perpetuates divisions between 'academic' and 'vocational' pathways. With reduced funds to adult learning, it also appears that the age-staged tyranny of compulsory education presents the main or only opportunity for individuals to transcend their family's social background (if that is what we take social mobility to mean). If nothing else this reaffirms governmental complacency in the face of ongoing social divisions. What remains of the 'social mobility' dimension of the policy rests on a reliance on supply-side intervention in the labour market (Keep 2006) while largely ignoring measures to adjust employer demand. Underpinning the whole approach is an ever less convincing fable about economic growth and the classic neoliberal assumption about social benefits accruing from a 'trickle-down' as a result of 'wealth creation' activities on the part of employers (Harvey 2005, 64-65).

From such evidence, a key effect of neoliberal policy appears to be the replication of social divisions and inequalities rather than any systematic or meaningful counteraction against them. For example, learners from socio-economically deprived areas are unlikely to have the same access to educational opportunities as those who live in more affluent areas who are more able to attend high achieving state schools or be privately educated (Duckworth, 2013). The recent area reviews for colleges of further education appear to have contributed to the geographical embedding of privilege and stratification by closing college campuses in urban areas with high levels of social deprivation and / or allocating curriculum in relation to the socio-economic profile of particular areas. 
Thus, for example, a college conglomerate formed from a number of merged colleges may locate its A level provision in an area with low levels of unemployment and a large proportion of high income households; meanwhile, for a campus situated in another area of the same city, with higher concentrations of working class households it might locate its vocational courses; on a third site, perhaps nearer to industrial districts, it might concentrate its apprenticeship courses. In terms of adult and community provision, the efficiency drive associated with the recent Area Reviews community 'outlets' and campuses were especially vulnerable (see Smith 2017). In that sense, the marketisation of further education, in this case through the imposition of 'efficiency' measures, can be seen to contribute to social inequality by allowing geographical concentrations of the cultural and economic capital that accrues to some classes to shape decision-making about the types of courses offered in different locations.

As Boeren (2016) has pointed out, there is evidence to show that students with high levels of achievement in compulsory education are more likely to engage in further education and lifelong learning. Participation statistics may well show that adult involvement is reducing (this is also occurring in Apprenticeships, see Tovey 2017) but this is a direct and predictable effect of the economisation of further education cultures. The manipulation of funding tariffs for adults in diverse circumstances since 2009 has created an uneven landscape. While Access to HE courses incur costs (often repaid by loans or through 'progression' arrangements) and costs for ESOL classes are similarly passed on to students, Apprenticeships are still, effectively subsidised by government. In a marketised system that is funding driven and policed to produce ever increasing efficiencies, the geography of available courses (or not) is as good an explanation as any for the so-called Matthew Effect. In this complex and commodified funding environment, the FE transforms project sought to identify parameters connected to transformative teaching and learning: the extent to which it is still occurring, the 'ingredients' that make it up and to gather narratives from teachers and learners and others about its impact.

It may not be surprising that the stratification that underpins the neoliberal purposing of education, with its entrenched academic / vocational divide and its newfound reliance on the mysterious capital of 'employability' alienates the students it brands as failures. We should remind ourselves that in 2016 just under a third (33.1\%) of young people did not achieve the national benchmark of 5 GCSEs at $A^{*}-C$ (OFQUAL 2016). The impact of this is considerable. As Dorling points out:

People and especially children crave recognition and respect. Telling children they have ranked low in a class is a way of telling them they have not earned respect. ... almost everyone wants to fit in, to be praised, not to rank towards the bottom, not to be seen as a liability as those as the bottom are seen. (Dorling 2014: 54)

In the neoliberal imaginary of which the so-called knowledge economy forms a part, for adults there are new ground rules. These rules impact on people and their lives. Being successful in the knowledge economy requires the acquisition of particular skills and competencies and the ability to adapt to a wide variety of knowledge domains. This mythology insists that people must be able to apply these skills effectively to partake in the ever-changing knowledge economy. Lifelong learning is envisaged as a mechanism for 
ongoing up-skilling, whereby a person must expect and make ready for transitions in her/his life (Field 2000, 2008; Field et al. 2009; Ade-Ojo and Duckworth 2015, 16, Duckworth and Smith 2017). This upskilling includes developing literacy/language/ numeracy skills as well as those associated with new and emerging technologies. As we noted above, the current funding landscape requires adults to be prepared to invest in their future. With further education courses for adults now requiring them to apply for a loan to cover tuition fees, financial considerations, particularly for those adults with families, are likely to impact strongly on the choices they make and it seems likely that the number of adults on courses will decline.

\section{The Research}

The FE in England: Transforming Lives and Communities research project ${ }^{1}$, sponsored by the University and Colleges Union, is a study that records and celebrates narratives about transformative teaching and learning in further education. Further education in England is comprised of colleges, training providers and work-based as well as community learning. In the current context of sustained budget cuts and Area Reviews, this chapter presents research findings that identify within further education a 'differential space' (Lefebvre 1992) in which learners, supported by critical pedagogy, are able to experience education as transformative - of themselves as learners but also as connecting them to new opportunities in life and work (Mezirow 2000; Duckworth 2013). Through more than fifty interviews and narratives that explore participants' educational journeys, the study probes a wide range of issues and can help to make sense of the impact of economic change and emerging social trends and how these play out in further education settings. When exploring adult education, the research illuminates how it relates to other factors in people's lives such as health and well-being, work, and family and community life. The research explores how adult education can draw on notions of 'self-invention', 'transformation' (Walkerdine et al. 2001) and 'bettering oneself' to provide a catalyst for hope and choice (Duckworth and Smith 2018).

\section{Connecting critical pedagogy to critical methodology:}

The research did not only focus on gathering evidence about the impact of adult learning on people and communities, but through a critical methodological approach, that conceptualised the research as a social practice (Herndl and Nahrwold 2000), it also affirmed participants' achievement and their positive learning identities. The methodological approach adopted for the study grew out of the critical literacy background of the researchers. Both researchers are experienced literacy educators and made the decision to deploy principles derived from critical pedagogy (Freire 1995, Breunig 2005) as an integral feature of the methodological approach. For that reason, care was taken to frame research conversations (we use this phrase in preference to the term 'interviews' to move away from the sense of an unequal and uni-directional relationship and distribution of power) to foster a sense of equality between the participants and the researchers. We met participants face to face, usually in the further education setting where they were studying. There, we attempted to generate an informal atmosphere by sharing stories and cups of tea in order to acknowledge that the research aspect of what we were doing was one part of a

\footnotetext{
${ }^{1}$ http://transforminglives.web.ucu.org.uk/)
} 
broader social encounter. Reciprocity was also important: we shared our own stories to establish openness and informality.

The research conversations provided participants with an opportunity to share their narratives, allowing for the sharing of obstacles and the solutions to overcome them. Through the medium of video, these narratives themselves then constitute capital which can be shared with and drawn on by others to inspire and offer strategies to move forward. Thirty five of the videos are individual narratives, fifteen are edited compilations centred on specific themes (e.g. Literacy, Women and further education). The research conversations were dialogical because stories were exchanged and opinions and feelings shared. The collective experience that the website enabled us to share challenges the neoliberal educational discourses which privilege individual over collective learning. The narratives are empowering and can take the form of a capital for resistance against the barriers faced by many learners, for example, struggling at school with reading and writing, being poor, labelled and stigmatised. Rather than the stories being hidden in shame the project participants took ownership of them and reclaimed them as stories of success while recognising the structural inequalities that they challenged and resisted to take agency in their lives and communities (Duckworth 2013, Duckworth and Smith 2019). Social capital (Field 2008) is not a homogenous resource equally available and accessible to all members of communities. For the project participants, who may have been constrained by factors such as class, gender or ethnicity, both they and their communities benefitted from the telling of their stories.

Other important features of the research conversations included the affirmative nature of the conversation. Once again, there is a connection here with critical pedagogy: the research positioned itself in such a way as to extend the affirmative regard that we see as underpinning transformative learning experiences. In other words, the conversations sought to affirm the positive learning identities that participants had re-discovered during their studies.

The research conversations also provided opportunities to document and build on what Tedder and Biesta refer to as 'narrative learning':

By narrative learning we mean that learning can take place as a result of articulating stories from one's life, through the process of talking about and reflecting on life experiences, in other words from the very narration of one's biography; and can take place as a result of presenting stories from one's life, by having stories with content and structure, by having a narrative that says something about what and how you have learned. (Tedder and Biesta 2009: 89)

In this way, the research conversations were positioned as an extension of the transformative teaching and learning experiences that were the central concern of the project. The learners described how they were able to be actively involved in decision making and dialogue with the positive outcome of a democratic environment and culture being co-constructed both inside and outside the classroom. For many of the learners and teachers, this inclusive approach to education and community action was the antithesis to what they had experienced previously. 
The project utilised a digitally orientated research methodology to gather, explore and share project data. The data comprised a series of rich narratives from learners, teachers, employers and learners' family members. These were collected through video recorded interviews which were then shared via a project website. Pink $(2007,96-7)$ discusses how using a video camera can disrupt the relationship between researcher and participant. The loss of eye contact when the researcher peers into the viewfinder can heighten the participant's awareness of 'being filmed'. In our project, the autofocusing equipment, with its large screen display, enabled us to set up the camera on a tripod, start recording and then to start the conversation, occasionally checking and refocusing. A Youtube channel ${ }^{2}$ and twitter account ${ }^{3}$ were further features of a multi-faceted digital platform that were used to create a project audience and an interactive critical space which garnered further contributions in the form of written accounts, photographs and artefacts. The use of these digital tools and the way they contribute to make the project data accessible can be seen as a way of "overcoming the 'silo-ing' of knowledge into discrete disciplines" that Halford et al. (2012: 186) see as an aspect of a "disciplinary carve-up of knowledge... \{that is\} the outcome of social and political struggles for identity, power and resources...." The digital platform was the catalyst to what we describe as virtually enhanced engagement adding to the data in an organic way and extending the influence and meanings of the project in the public domain for example by connecting the researchers directly with a key policy maker. The sharing of the narratives - with the consent of the participants - across the public domain facilitated the power of the collective over individual approaches. The website became a vehicle for the co-construction of a virtual community bringing together learners, teachers, academics, activists, policy makers. Project participants' voices in this way were able to reach out and cross different domains to challenge stereotypes and unsettle hegemony. The first year of the project culminated in a conference that brought together participants from across the country: students, teachers, researchers, employers and policy influencers.

\section{Ethics}

The use of a digital platform with a particular focus on video in the project brought up a number of ethical considerations. The project was scrutinised by the Ethics Committees of both researchers' HEIs. We offered all participants anonymisation at the recruitment stage, but as the focus was on the transformative qualities of their educational experiences, most wanted their real names to be used. Each video was edited and then shared with the participant prior to publication. Re-edits were undertaken at the participant's request. The emphasis throughout was on maintaining their dignity while presenting their stories in their own words. The stories of many were closely connected to particular colleges and even specific teachers. Where these were mentioned, we also sought permission to include these. The publication of videos on Youtube raised the issue of the need to remain aware of public comments and to respond, edit and delete these where appropriate. We adhered closely to the BERA ethical guidelines (2011) throughout.

\section{Findings}

\footnotetext{
${ }^{2}$ https://www.youtube.com/channel/UCkDeirtGCmeBs361BgibXnA

$3 @$ FEtransforms
} 
In this next section we will share some of the participants' narratives. We analysed the data thematically by identifying recurrent themes and exploring these through a range of theoretical concepts. We have selected these particular participants as they are illustrative of key themes relating to the aspects of further education that we categorise as transformative. Adult learning can be transformative in the way it empowers individuals and communities. By empowering here we mean enabling students to rediscover their agency and themselves as learners in cooperative and egalitarian learning spaces. Empowerment can feel overused as a term and its meaning compromised. But we use it to describe how participants were able to reposition themselves not as free-floating individuals in the entrepreneurial individualistic sense but as beings rooted in communities and able also to move into new and different spaces and in effect to change their positionality in the social world - and move away from labels and identities that may have been imposed on them. The use of digital media contributed to the notion of transformation here in the sense that not only did the research practice affirm participants' new and emerging identities, but through the presentation of their narrative via a video posted on the project website, participants could see themselves as belonging to a "hybrid community" centred on TTL. James and Busher describe the crossover between physical and online communities in this way:

Communities have always overlapped and been part of wider constellations, but the development of cultures that have become multifaceted through media development, telecommunications, computer-mediated communications, has created hybrid sites of social interactions for individuals and communities where practices, meanings and identities are constructed. (James and Busher 2013: 195)

This sense of belonging through a shared experience might be virtual to begin with, but the website offered the potential for online networking with others who shared experiences of TTL and face to face at the project conference that took place eighteen months into the research.

\section{i) Transformative Teaching and Learning as a lifeline of hope}

Schools are sites where identities and futures are formed and the Transforming Lives project traced the sometimes detrimental impact of that. Rather than being sites that offer an egalitarian model where everyone is on an equal footing, schools are often experienced as sites of inter-generational marginalisation, social exclusion, and labelling by teachers and peers, our research revealed. For some learners this is experienced as symbolic violence. Their bodies were sites for symbolic violence, which affected their experience of education and had a huge impact on their learning experience, how they define themselves and their subsequent trajectories. For adults in further education settings, transformative teaching and learning experiences often involve a revisiting and a revisioning of the spoilt learning identities created in primary and secondary education by the labelling process which targeted them for being poor and struggling with educational achievement.

Anita, a female participant from the North East of England, provides an example of someone who was regarded as a failure at school, in this case because of undiagnosed dyslexia: 
I've always been told I was thick. Always been told I was stupid.... The teachers at school assumed I was born to fail. Dyslexia... had (only) just been identified. So you were thick, you were stupid and if your parents didn't even have any faith in you, you're not going to have any faith in yourself.

Anita describes how her dyslexia was not addressed at school. In child and adulthood, she felt stigmatised and struggled with being dyslexic. However, she gradually accumulated a body of experience in her working life that signalled administrative, organisational and interpersonal abilities. Encouragement by her partner and a chance opportunity to stand in as a project manager led to her resuming her education. Anita's tutors were key in building on this.

In eighteen months, I'll be a qualified social worker. My tutors are the ones that got me here... They encouraged me. They never once doubted me. They made me grow... They are the first people, apart from my partner who ever had any faith in me.

Her story shows us how further education can offer opportunities that build confidence in learning environments with an affirmative culture. This in turn facilitates the development of new knowledge and new identities. We would not separate teaching and learning in any analysis of these transformative experiences. Transformative teaching and learning (TTL) environments offer a dialogical experience that involves students in learning interactions with teachers and other students. These commonly draw on students sharing understandings of their prior learning experiences as a basis for moving forward.

For Anita, TTL has meant:

I am actually going back, doing something and not just sitting in a cakey shop. And now I have my bits of paper, I have my confidence, I have my voice and I have a future. That's what education has given me: a life, a new life, a better life. It just opens up a whole new world and a whole new you. Suddenly, people are seeing you as you really are and not in the box that they have put you in.

The Foucauldian notion of the 'subject as an effect of power' (Foucault 1982) can help us understand the impact of TTL. Her transformative learning experience has impacted on her identity as a 'subject'. Here the subject is not just how we regard ourselves but maps across to how the person we are features within the different power networks that we connect to. This isn't just about self-esteem but involves her sense of social standing and status as she interacts with others in wider society. A corollary of this is that TTL also heralds changes within existing social networks and the connection to new and different social networks.

I can now talk to people that I've never felt I could talk to: the doctor, the clinician. But now I have my bits of paper..., I have can talk and I ha e valid points to make. And I have a voice. If it wasn't for college, I wouldn't have that voice.

Anita's account is important in the way it emphasises how her life experience, including suffering bereavements and moving away from abusive relationships fed into her choice of career, in this case social work. It seems appropriate to use the term 'vocation' to describe her enthusiasm and commitment to this career. In choosing it, she is drawing on her 
existing experiential capital and potentially, through her work, affirming her own journey as she interacts with people in her work.

I now want to be that person where I can say: 'Come to me I can help. I can give you the tools and as much support as you need to get you to a better place.' Whether that's out of an abusive relationship, whether it's parenting skills, whether it's education so you can have the better job so you can have a better life for you, your kids, your family. I have moved, maybe not physically but mentally, emotionally and I've grown.

In addition to providing evidence about the impact of TTL on the self as subject, Anita also talks about how her learning journey brought about a change of expectations in her family:

Through that, I've been able to inspire my kids. One's at Manchester University... he's in his final year. My daughter wants to go to Oxford to do Medicine. My oldest one has gone into the building trade and is doing fantastically well. He's gone into the management side. He would never have done that but he saw that I could do it. If mum can do it, I can do it. I like to think I have inspired them.

What we have called the ripple effect of TTL extends from the individual, to their families but also beyond that and into the communities in which they live. A concrete example of this comes from Anita as she talks about how, since returning to further education, she has actively persuaded others to do the same:

I love people.... There isn't anyone that I have met who hasn't got some good in them, something you can bring out and something you can nurture. There's a girl that I met... she's just started her foundation degree in Health and Social Care. I persuaded her to do access...I met her in a pub, she was in bad place. She started coming in for a chat. I encouraged her. Over a period of time she did the progression course.... Another one that I've recommend: a young lad in the village... I absolutely badgered him. He was good kid going to waste. He's a hard worker. He just needed direction. He saw the resources that they've got (in college) and he was in his element. He signed up there and then. He's settled... it's lovely to see.

In this passage, Anita illustrates how she became an advocate for returning to education in informal social spaces within her community. There are two points to make here: first it seems inconceivable that the two people she talks about would have returned to education without her intervention. Her intervention provides an illustration of how further education that is embedded in communities is less likely to have an issue with accessing 'hard to reach' students and communities. In this way, her interventions also reveal the hollowness of notions of marketing and public relations that underpin the commodification of further education in these neoliberal times and that may be governed by commercial interest rather than the care and concern informing Anita's actions.

David, a participant from a traveller background, began attending literacy classes in Rochdale and spoke about how being unable to read and write made it difficult to navigate through everyday social encounters: 
When you can't read and write out there, it's really hard. And it's scary. Now I can actually read and write and sign my own name. When I go to the doctor I can sign a note... You need education to learn about everything that's going on outside.

What's striking about the passage is David's use of the word 'fear'. This stemmed not just from an inability to decipher a given text but the uncertainty that comes from not knowing when you might next be called on to do so. David's reasons for not being able to read and write stemmed from his childhood:

I had a bit of a bad childhood..... I didn't really have help while I was at school. I'm an English gypsy so I was raised in a travelling family. So it was quite hard. I never went to school, I went to work instead. There's a lot of people in the travelling community, mostly with the boys they don't read and write, a lot of them don't. It's normally down to the women to do that kind of thing, the reading and writing of letters and things. Like the gas and the electric bills and all that: They normally sort all that out. The men normally go to work. (At) about eight I went to work. Started working with my dad, till I was about fifteen or sixteen......

In this example, David's motivation to improve his literacy skills is in effect a way of ensuring his children have more choices than he had. TTL in David's case is about breaking intergenerational patterns of poverty through education. David stressed how learning to read would enable him to get his driving licence. This clearly connected in his mind to being able to work. But the primary motivation David had for learning was connected to his role as a father: he wanted to be able to read bed-time stories to his four-year-old daughter:

I've got a bit more confidence, I never had much confidence. I couldn't read at all. Now I've started picking up words. It feels great. My little girl, she used to read stories to me and I couldn't read stories back to her. But now I can actually read back. It feels brilliant. It's only from coming here that I've got that... You can do these things, you've just got to want to do it.

For David then, an effective way in tackling his literacy issue was to focus on habitual practices with a finite number of texts, so that these could be revisited in a safe environment. Bedtimes stories offered him the perfect opportunity. Children have favourite stories and enjoy hearing them repeatedly. Claiming literacy was also a catalyst for David to take part in our democratic processes.

I never voted in my life ever. I sat down and read the thing that came through the letterbox and I thought yeah I'll give that a go. And I voted for the first time. I'd never ever voted before and you need to vote. Everyone needs to vote. Now I can actually read and write and sign my own name. When I go to the doctor, I can sign a note... You need education to know what's going on outside: the politics and all that. I'd never voted in my life, ever. I read the thing that came through the letterbox and I voted for the first time.

While David had moved away from his traveller background, the impact of participation in adult learning has clearly had a multi-faceted impact on him in the community that he and his family are now a part of. Not only has his further education given him confidence in a 
range of everyday social situations, crucially, it has also given him entry into our democratic practices.

Nyomi was another project participant that we met in the north east of England. The narratives of participants in this area of the country all carried a historical subtext dating back to the Miners' Strike of the early 1980s. The mining villages surround Durham were severely affected by the pit closures that happened in the wake of the dispute. Many villages often depended on the mines as the main employer in the area. Consequently, pit closures resulted mass unemployment and on future job prospects. A mother with a young daughter, her story was one that involved completing a Diploma in Youth work but then finding, as a result of local authority cuts, that there were no jobs in that area of work either. This, coupled with her responsibility as a carer for her partner isolated her and had a negative impact on her mental health.

I kind of spiralled into quite a bad depression. I got pregnant, had my daughter and luckily my daughter gave us a little bit of a boost, so I went and got help for my depression... It was the Health Visitor that spoke to us and tried to get us to get a little bit of motivation and to go back out into the world and try again.

In Nyomi's case, being on benefits carried a social stigma. She talked about the way she and her partner were 'looked down on' by neighbours while they were unemployed and on benefits. Nyomi's hopes for the future and plans were affected by the economic and employment conditions of the local area added to complex personal and family circumstances. Enrolling on an Access to HE course and having support for her dyslexia provided Nyomi with an opportunity to experience TTL. Nyomi talked about the ripple effects of her further education and the benefits for her family.

I became a mam of somebody with a health condition. That was who I was. I wasn't who I had been. As soon as I got depression I went on a downward spiral. I found it very difficult going out... I had spent the last four years extremely depressed because of the way my life was panning out. I didn't think... I didn't see myself in education again. And it's hard when you come from living and not having a job and you know that you should be working... and nobody employing you... The only thing I could do to give my daughter some kind of life was to do the Access Course. It's been amazing... I came off antidepressants which I'd been on for quite some time. I made friends with people. And I haven't really spoken to a lot of people in years. It really does change your life. It's allowed me to get back out... Within two months I was a completely different person

Nyomi's narrative is important because it shows how adult education has a role in providing opportunities for people who are caught up in geographically specific socioeconomic circumstances. While the impact of these circumstances are felt by individuals on a social and physical level, locally situated adult education opens doors that offer people hope. Nyomi's further education did not involve her signing up for a 'retraining package' important as such initiatives might be - rather, it was accessed informally, almost as a form of social prescription. Nevertheless, its impact has clearly been massive and has resulted in renewed hope within the family unit. 
I went from being in the house all the time or going to hospital appointments with my daughter to having something to look forward to. It (also) changed my partner into a more confident person. We were both in quite a bad situation when we were depressed because he was depressed too - but his was more to do with his health. So giving him some extra responsibility... he changed completely. Two years ago, he would never have gone back to college because he just didn't have that confidence. So he hid away from a lot of things.

Nyomi's narrative illustrates how adult education offers a way out of despair and how this positive impact fed into her family situations. Clearly, the transformation of her aspirations is likely to impact on the dynamics of the family and on her daughter's well-being. Nyomi's empowerment as a student fed into her confidence and the value she felt in her role as a mother and partner.

\section{Discussion}

In this next section, we will reflect on the current state of adult education in the UK and comment on what we have learnt from the narratives we have gathered.

\section{i) Class matters in times of austerity}

Since the 1980s research and debates surrounding class may be seen as being side-lined in political discourse. Indeed, notions of class loyalty and solidarity, in many ways, were torn apart under Thatcherism. In $1997 \mathrm{New}$ Labour came into power. This heralded a reinvigoration of conservatism and the notion of a classless society was seen and heard in party rhetoric of meritocracy and equal opportunities. Individualism and self-improvement were driven under this premise as were ideas that 'talent' was based on ability rather than privilege (Lucey and Reay 2002; Reay \& Lucey 2003; Reay 2004). These ideologies were deeply embedded in the neo-liberal rhetoric of 'choice for all'. However, there is overwhelming evidence that in economically unequal societies, those with enhanced resources/capitals are in the best position to make choices and those who are at a structural disadvantage who may be poor or who have grown up in economically depressed areas, have much more limited options (Ball et al. 2000; Ball 2010, Duckworth and Smith 2017).

The notion that class identities have diminished in significance over recent decades is also a key feature of some contemporary social theory. This may be seen as a result of the cultural shifts aligned with individualisation, de-traditionalisation and post-modernism (for examples, see Beck 1992; Giddens 1991; Bauman 1987, 1998). The idea of class going 'out of fashion' was a consequence of post-modern thought with its emphasis on multiple identities, an atomised social reality and its challenging of the 'grand narratives' that provided the underpinning for much Marxist thought at the time. The forces of globalisation including the demise of the USSR trumpeted by Fukuyama (1989) as signalling the 'triumph of the West, of the Western idea' and 'the total exhaustion of viable systematic alternatives to Western liberalism', appears however to have reconstituted society in ways which mean social class remains a powerful explanatory concept.

Our study argues that class still plays a key explanatory role in understanding educational trajectories today. This is reflected in the narratives of adult participants in the study. Many expressed feelings about having been written off as 'thick' at school (Anita) and having to 
battle with teachers' and others' low expectations. This data challenges the trend of political dismissal of class and instead places it as a key thematic strand that explains the way people are oppressed and communities are silenced. If sociologists and educationalists are to understand how social class and gender impact on adult education, it is vital to trace the links between people's experience of schooling and to recognise how further education is able to reconfigure the trajectories set by these negative experiences of schooling, enabling people to fulfil their real potential and giving them hope.

\section{ii) Social, cultural and educational capitals matter}

Beck (1992) and Giddens (1992) discuss the move from traditional relational customs, to 'detraditionalisation' and individualisation. They argue that the significance of class, gender, family and religion is fading and that tradition is being replaced by individualisation and personal fulfilment in relationships. We could argue this is a simplistic analysis and that structural inequalities such as class, gender and ethnicity continue to shape people's lives and trajectories. Social, cultural and educational capitals impact upon so-called 'freedom of choice'. Under these lenses, the notion of individualisation is problematic. Friends and family in our research provide important sources of social and emotional capital. Adult education offers spaces in which these capitals can be enhanced. Anita, David and Nyomi all spoke about the importance of the supportive relationships they experienced in the 'differential space' of the further education settings they accessed. These affirming relationships encompassed those with teachers but also with other students. The role of teachers was in nurturing and sustaining a learning environment founded on dialogical and collective learning and this was underpinned by an ethic of care (Feeley 2014).

According to the neoliberal model of rational economic 'man', social mobility is about the individual improving her/his economic prospects within existing social circumstances perhaps with some positive spillover into the life chances of the individual's immediate family. But in our research social mobility meant more than this. It was more than individual, instead it connected strongly to changing family circumstances and cultures and orientating these towards education as a public good. It also entailed a raising of a broad critical consciousness that was retrospective in terms of helping adults to understand the background to their educational (non) attainment to date and involved a forward-looking orientation that often included the individual's wider community. In our research, TTL takes account of existing social cultural and education capital and uses these to springboard renewed agency and progression. TTL involves subverting deficit labels and the lack of confidence derived from negative prior educational experiences, re-building self-esteem and (re)constructing positive educational identities.

\section{iii) Communities matter}

Further education providers are embedded in communities in a way that no other educational institutions are. Not only do they have historical roots that connect them to industry and employment but, unlike schools, they have populations that draw on diverse communities beyond neighbourhood boundaries. Critical in this positioning is the history of each provider - many colleges have grown out of particular needs and economies which connects them strongly to their context and situations. The communities from which Anita, David and Nyomi come were important industrial locations. But with the demise of Rochdale's textile industry and the pit closures in the north east, local communities have 
been hit by unemployment and poverty has escalated. Now, both areas are a tapestry of cultures and ethnic groups. While old industries may have withered away and certainly can no longer offer the kind of long term stability that was once on offer, colleges are still connected to local employers and industries.

Many project participants made it clear that further education colleges were important because they provided spaces of social cohesion in which people from different ethnic backgrounds could mix and interact. The colleges we visited as part of the project had roots woven into the social/cultural and economic fabric and history of the landscapes they inhabited; landscapes that shaped the lives of the learners that came through their doors. For example, when talking to learners on Access to HE provision at a college in the north east, it became clear that while the college was drawing in students from outlying villages that, until the mid-1980s, had been economically dependent on coal. The communities in these villages had a legacy of unemployment and the associated impact of this in terms of poverty, health and well-being. In that sense, 30 years after pits had closed, the college was still addressing the impact of the closures, providing education and employment opportunities for young people and adults, offering them hope, real career choices and, as a corollary, a way out of cycles of mental ill-health. Nyomi's story powerful testimony of this.

\section{Formulating some recommendations for policy and practice}

Our research provides evidence that despite the instrumentalisation of the curriculum in further education colleges, TTL is still taking place. Transformative education through the enactment of a curriculum that challenges rather than reproduces social inequality, offers a frame for understanding learners' accounts of their educational and personal journey. What do these examples imply for policy and practice?

One remarkable aspect of the narratives is that the social benefits of each of the participants' journeys are far greater than the achievement of a single (funded) qualification. This is illustrative of the idea that the further education that colleges provide is about more than 'just' the achievement of funded qualification aims. For this to become a reality though, a change to the way further education for adults and young people needs be effected. While colleges and other providers are incentivised to organise their provision in order to garner maximum returns, rather than to focus on addressing individual and community needs, further education will continue to be dominated by performativity and gaming. Despite policy rhetoric trumpeting the need to put the student 'at the heart' of the process, current funding arrangements objectify students: their interests are subordinated to colleges' financial bottom-line - and this has been intensified under austerity. This has to change.

This first point also suggests that further education requires a particular kind of leadership, one that is ethically-grounded and driven by the voices and needs of local communities. What is needed is college leadership that sees value (unmeasured by funding metrics at present) in engaging with community organisations and in community outreach.

Furthermore, it needs to fully appreciate and facilitate the powerful ripple effects of transformative learning, understanding how it deeply benefits not just individuals (like Anita, David and Nyomi) but their families and local communities too. Ultimately, this kind of conscious, ethical leadership connects with our country's democratic culture. 
Finally, further education in England bears the marks of OECD knowledge production and policy-think - what Grek calls the 'new technology of the governance of the European education space through indicators and benchmarks' (Grek 2008: 215). It isn't hard to view the impact of PISA data and the influence of the OECD in general as 'deeply penetrating and consciousness-moulding' (ibid.). One consequence of this is the continued reification of the abstract space conjured into being by the term 'FE sector'. This abstract language not only disguises the hugely heterogeneous nature of the different contexts in which teaching and learning take place but is also a totalising strategy that enables policy interventions that impose neoliberal meanings on what is better thought of as local educational provision. To move away from the abstraction of ' $\mathrm{FE}$ ' is to assert that there is no singular experience of further education; just as there are multiple compulsory educations that 'work' better for some individuals and social groups than others, in the same way, there are multiple further educations. Within a broad canvas in which the structures and cultures that shape further education have been decisively governed by an instrumentalist agenda, spaces still exist in which transformative teaching and learning takes place. But TTL depends on an ethos which does not seek to objectify students within a 'skills discourse'. While TTL may see a student's social class as a starting point, it doesn't use that background to label, impose restrictions and limit expectations. TTL by definition is about overthrowing the institutionalised symbolic violence which seems to be so much a part of the neoliberal conceptualisation of education/employment. TTL as experienced by adults is also strikingly individual, following distinctive and by definition not-standard pathways. In many ways it can be regarded as a necessary compensation for an overly normative compulsory education system.

\section{Conclusion}

The implementation of austerity measures has hit further education budgets particularly hard. We are now in a time and space where the gap between the richest and poorest has grown to its widest for several generations (Savage 2015) and policy reform, governed by the monetarist principles of austerity, is hitting the most vulnerable hardest. Education has a central role in the pursuit of social justice, and is pivotal to the sustained challenge to injustice. Educators are at the helm of this.

Interestingly, the current harsh funding environment has thrown the significance of TTL into sharp relief. Austerity has meant not just a reduction in funding but the consolidation of managerialist cultures (see Smith and O'Leary 2013) that undermine holistic pedagogies. Despite these hostile conditions, there is still evidence of students experiencing education as transformational. But a transformative approach to education that aligns with social justice means more than replacing the existing dominant frame with another that fails to attend to the structures of power underpinning the ways in which we position learners from marginalised backgrounds. The case studies of participants are based a dialogic engagement which emphasises listening and importantly sharing our experiences. This requires a conceptualisation of the theoretical and methodological issues involved in understanding and representing educational practice that includes the practices, knowledge and skills that learners bring into the classroom. The real-world experiences of our learners are a crucial component for thinking about how to incorporate transformational approaches in education; integrating discussion about society, representation, power, and ideology is a tool for consciousness raising, transformation and hope. Care and solidarity, driven by dialogue 
with learners, offers new imagined possibilities that flow to the learners, their families and their communities.

\section{References}

Ade-Ojo and Duckworth (2015). Adult Literacy Policy and Practice: From Intrinsic Values to Instrumentalism. London: Palgrave Macmillan Pivotal.

Ade-Ojo, Gordon and Duckworth, V. (2016) Of cultural dissonance: the UK's adult literacy policies and the creation of democratic learning spaces. International Journal of Lifelong Education. volume 36 and issue 4

Ball, S., Maguire, M. and Macrae, S. (2000) Choice, Pathways and Transitions Post-16: New Youth, New Economies in the Global City. London: Falmer Press.

Ball, S. J. (2010) 'New class inequalities in education: why education policy may be looking in the wrong place! Education policy, civil society and social class', International Journal of Sociology and Social Policy, 30 (3/4): 155-166.

Bauman, Z. (1987) Legislators and Interpreters: On Modernity, Postmodernity and Intellectuals. Cambridge: Polity Press.

Bauman, Z. (1998) Globalization: The Human Consequences. Cambridge: Polity Press.

Beck, U. (1992) Risk Society: Towards a new modernity. London: SAGE.

Becker, Gary, S. 1993. Human Capital, A theoretical and empirical analysis with special reference to education. London: University of Chicago Press.

Biesta, G., \& Tedder, M. (2006). How Is Agency Possible? Towards an Ecological Understanding of Agency-as-Achievement. Learning Lives: Learning, Identity, and Agency in the Life Course.

Working Paper Five, Exeter: Teaching and Learning Research Programme.

Boeren, E. 2016. Adult lifelong learning participation. London: Springer

British Educational Research Association. 2011. ETHICAL GUIDELINES FOR

EDUCATIONAL RESEARCH. https://www.bera.ac.uk/wp-content/uploads/2014/02/BERA-

Ethical-Guidelines-2011.pdf?noredirect $=1$. 29.01.18.

Davies, W. 2014. The Limits of Neoliberalism. London: Sage.

Dorling, D. (2011) Injustice: why social inequality persists, Bristol: Policy Press.

Duckworth and Smith (2017) Further education in England - Transforming lives and communities: Interim Report. London: UCU.

Duckworth, V. and Smith, R. 2018. Transformative Learning in English Further Education, in Borg, C; Mayo, P and Sultana, R (ed) Skills for sustainable Human Development of the International Handbook on Vocational Education and Training for changing the world of work.

London: Springer.

Duckworth, V. (2013). Learning Trajectories, Violence and Empowerment amongst Adult Basic Skills Learners. Routledge Research in Education: London.

Duckworth, V. and Smith R. 2019. Research, criticality \& adult and further education: catalysing hope and dialogic caring. In Hamilton, M and Tett, L. 2019. Resisting the neo-liberal discourse in Education: local, national and transnational perspectives. London: Policy Press. Feeley, M. 2014. Learning Care Lessons: Literacy, Love, Care and Solidarity. London: Tufnell Press.

Field, J. (2000) Lifelong Learning and the New Educational Order. Stoke-on-Trent: Trentham Books.

Field, J. (2008) Social Capital. London: Routledge. 
Field, J., Gallacher, A. and Ingram, R. (eds) (2009) Researching Transitions In Lifelong Learning. London: Routledge.

Foucault, M. 1982. The Subject \& Power. Critical Inquiry. 8(4) 777-795.

Fukuyama, F. 1989. The End of History.

https://ps321.community.uaf.edu/files/2012/10/Fukuyama-End-of-history-article.pdf.

15.11.17.

Giddens, A. (1991) Modernity and Self-identity: Self and Society in the Late Modern Age.

Cambridge: Polity Press

Grek, S. (2008) 'From symbols to numbers: the shifting technologies of education governance in Europe', European Education Research Journal, 7(2), 208-218.

Halford, S. Pope, C. and Weal. M. 2012. Digital Futures? Sociological Challenges and opportunities in the Emergent Semantic Web. . 47 (1), 173-189.

Harvey, D. 2005. A Brief History of Neoliberalism. Oxford: Oxford University Press.

Herndl, C. \& Nahrwold, C. 2000. Research as Social Practice. Written Communication: 17 (2), 258-296.

Hope, M. 2002. 'New Labour's Policy on Inclusion: will practice match principles?', Forum: for promoting 13-19 comprehensive education, 44 (3): 93-98.

James, N. \& Busher, H. 2013. Researching hybrid learning communities in the digital age through educational ethnography, Ethnography and Education, 8:2, 194-209.

Keep, E., 2006. "State control of the English education and training system - playing with the biggest train set in the world." Journal of vocational education \& training, 58 (1): 47-64.

Lucey, H. and Reay, D. (2002) 'A market in waste: psychic and structural dimensions of school-choice policy in the UK and children's narratives on "demonised" schools', Discourse, 23: 3, 253-266.

OFQUAL. 2016. A guide to GCSE results, summer 2016.

https://www.gov.uk/government/news/a-guide-to-gcse-results-summer-2016. 1.12.17.

Pink, S. 2007. Doing Visual Ethnography. London: Sage.

Reay, D. and Lucey, H. 2003. 'The limits of "choice": children and inner city schooling', Sociology, 37 (1): 121-142.

Savage, M. 2015. Introduction to elites: From the 'problematic of the proletariat' to a class analysis of 'wealth elites'. The Sociological Review, 63:2, 223-239.

Smith, R. 2015. College re-culturing, marketisation and knowledge: the meaning of incorporation, Journal of Educational Administration and History, 47:1, 18-39.

Smith, R. 2017. Area Reviews and the end of incorporation: A Machiavellian moment. In Daley, M., Orr, K. and Petrie, J. 2017. The Principal. London: UCL IoE Press.

Smith, R. and O'Leary, M. 2015. Partnership as cultural practice in the face of neoliberal reform, Journal of Educational Administration and History, 47:2, 174-192.

Tedder, M. and Biesta, G. 2009. .... In Field, J. Gallacher, J. and Ingram, R. 2009. Researching Transitions in Lifelong Learning. London: Routledge.

Tovey, A. 2017. Apprenticeship levy behind 60pc collapse in number of people starting training courses. Daily Telegraph. 23 November 2017.

http://www.telegraph.co.uk/business/2017/11/23/apprenticeship-levy-behind-60pc-collapsenumber-people-starting/. 27.11.17.

Walkerdine, V., Lucey, H., and Melody, J. (2001) Growing up Girl: Psychosocial Explorations of Gender and Class. London: Palgrave. 